\title{
The trend of natural illuminance levels in 14 Chinese cities in the past 50 years
}

\author{
Ying $\mathrm{He}^{1,2^{*}}$, Aiying Wang ${ }^{3}$ and Haijing Huang ${ }^{1,2}$
}

\begin{abstract}
Background: Maximizing natural illuminance, seeking sustainable ecological development, and saving electricity are very important. The annual total natural light illuminance values of 14 typical Chinese cities in different climate regions were obtained in this study based on solar irradiance data of the cities in the past 50 years (from 1961 to 2010). A luminous efficacy model was integrated in the analysis of data. This study analyzes the overall and inter-annual change trends of total natural light illuminance values in each city.
\end{abstract}

Methods: Mann-Kendall test method or nonparametric test method can reveal the changing trend of time series; the method does not require samples to follow a specific distribution and cannot be affected by a few abnormal values. The method is suitable for data with abnormal distribution. In this paper we analyze the trend of natural illuminance levels in 14 Chinese cities by Mann-Kendall trend analysis and Mann-Kendall mutation test.

Results: The results show that the overall change trends in the annual total natural light illuminance values in Beijing, Guangzhou, Urumchi, Xian, Xining, Shanghai, Changsha, and Chongqing are extremely obvious; the change trend in Erenhot and Kunming are obvious; and those in Changchun, Yushu, Heihe, and Fuzhou exhibit no change. The inter-annual change trends in the total city illuminance values in Chongqing and Urumchi decreased gradually year by year; those in Beijing, Shanghai, Changsha, Guangzhou, Erenhot, Xian, Xining, and Heihe increased at first and decreased in the later years. The illuminance values in Changchun and Yushu increased initially, decreased, and then increased again; in Kunming, these values decreased initially, increased, and then decreased again.

Conclusions: The annual total illuminance values of natural light in some cities significantly decrease, thus affecting the accuracy of architectural daylighting design. The total change trend of natural light illuminance has an insignificant association with Chinese light-climate regions.

Many factors influence natural illuminance: the major factors are cloud cover and aerosols from air pollution; the minor factors are water vapor, atmospheric molecular scattering and absorption, and solar activity.

Keywords: Solar irradiance; Luminous efficacy; Natural illuminance; Mann-Kendall test

\section{Background}

Energy continues to become increasingly scarce. Maximizing natural illuminance, seeking sustainable ecological development, and saving electricity are therefore very important. Daylighting climate data are the basis for the application of natural light in buildings; illuminance data is one of the core contents of daylighting

\footnotetext{
* Correspondence: he_ying@cqu.edu.cn

${ }^{1}$ Faculty of College of Architecture and Urban Planning, Chongqing University, Chongqing 400045, China

${ }^{2}$ Faculty of Key Laboratory of Chinese Education Ministry for Construction and New Technology of Mountain Cities, Chongqing University, Chongqing 400045, China

Full list of author information is available at the end of the article
}

climate data. China has a vast territory; different regions have different daylighting climate. Daylighting climate data including cloud cover, cloud form, sunlight condition, solar elevation, atmospheric mass, direct illuminance, diffuse illuminance, and globe illuminance were obtained in a study from 14 cities through two consecutive years of observation of natural light (1983 to 1984) in typical Chinese light-climate regions [1]. China was divided into five daylighting climate zones according to natural light distribution and designed daylighting design standards [2].

The International Daylighting Measurement Program (IDMP) was implemented in 1991 by Commission

\section{实}

(c) 2013 He et al.; licensee Springer. This is an open access article distributed under the terms of the Creative Commons Attribution License (http://creativecommons.org/licenses/by/2.0), which permits unrestricted use, distribution, and reproduction in any medium, provided the original work is properly cited. 
Internationale de l'Eclairage (CIE) to acquire daylighting climate observation data from several cities (including Beijing and Chongqing in China) throughout the world [3]. Under this program, measuring stations throughout the world participate in a coordinated effort of daylight availability recording. Stations fall in two categories: the general class, in which illuminances and irradiances are the principal quantities measured, and the research class, in which the stations make continuous recordings of sky luminance distributions, as well as of illuminance, irradiances, and other meteorological quantities [4]. After this event, daylighting climate observation research did not undergo further development.

As the visible part of solar irradiance, natural light has a close relationship with solar irradiance. Data on solar irradiance are abundant owing to the regular observation project of the meteorological department. Therefore, natural illuminance data can be obtained through solar irradiance. However, luminous efficacy is the key factor in obtaining illuminance data from solar irradiance. Luminous efficacy is the ratio of natural illuminance to solar irradiance.

Several authors have suggested models to derive the luminous efficacy for different sky conditions. Little air [5] and Aydinli and Krockman [6] presented polynomial relations of different degrees using solar altitude as the only independent input variable for beam luminous efficacy. Another model, which also uses solar altitude as an independent variable, was proposed by Robledo and Soler [7]. Littlefair established diffuse luminous efficacy as an interpolation between overcast and clear sky using sky clearness as an indicator. Using Littlerfair's model, Chung [8] and Robledo et al. [9] developed local luminous efficacy models (based on data from Hong Kong and Madrid, respectively) for overcast and intermediate skies. Perez et al. [10] developed a luminous efficacy model for all sky types as a function of the solar zenith angle $(Z)$, atmospheric precipitable water content $(W)$, and the sky brightness index $(\Delta)$. The coefficients of these variables were specified as a function of sky clearness ranges.

$\mathrm{Wu}$ et al. proposed a monthly and annual luminous efficacy model by combining China's daylighting climate observation data to meet the requirements of daylight climate zones and daylighting design.

Solar irradiance values throughout the world have changed greatly in recent years as a result of the changing global climate [11], worsening atmospheric pollution [12], and a rapid urbanization process [13]. Consequently, natural illuminance has also changed. However, only very few relevant reports examine the changing characteristics and trends of natural illuminance.

\section{Methods}

\section{Acquisition of natural illuminance data}

Although several cities in China have accumulated annual light climate observation data, more long-term and large-scale light climate observation data are required to determine the changes in China's daylighting climate. Abundant irradiation data are necessary to acquire illuminance data.

\section{Luminous efficacy model}

Irradiance data can be obtained from the relevant meteorological observatories; luminous efficacy $K$ is the key factor in obtaining data on outdoor natural illuminance. Many types of luminous efficacy models have been proposed; the selection of model parameters and the accuracy of these models differ. The monthly and annual luminous efficacy model proposed by Wu et al. [1] has a relatively high accuracy. Its relevant parameters can be obtained from meteorological observation data suitable for determining daylighting climate characteristics. This model was utilized in the present study to obtain natural illuminance values in China. The model considers four factors as parameters. These factors are geographic latitude, altitude, vapor pressure, and sunshine duration. A quaternary simple linear regression equation (Equation 1) was established in this study by integrating annual $K$ values:

$$
\begin{aligned}
K_{G}= & 142.1748-0.3757 \times N+0.0008 \\
& \times H-0.4147 e-0.0853 \times T
\end{aligned}
$$

In the equation, $K_{\mathrm{G}}$ is the value of annual luminous efficacy $\left(1 \mathrm{x} / \mathrm{w} \times \mathrm{m}^{-2}\right) ; N$ is geographic latitude $\left({ }^{\circ}\right) ; H$ is altitude (m); e is annual or monthly vapor pressure $(\mathrm{h} P \mathrm{a}) ; T$ is monthly average sunshine duration (h).

\section{Data sources}

Radiation data, geographic latitude, altitude, vapor pressure, and sunshine hours were obtained from the China National Meteorological Information Center.

Radiation data, geographic latitude, and altitude were obtained from the data set of annual radiation values in China. The radiation data set consists of multi-element, multi-station, single-year files from 122 Chinese meteorological stations reported in the 'radiation monthly report' after statistical processing. The meteorological stations used the following observation instruments: radiation measurement instruments used before 1993 were the pyroelectric (constantan, manganese steel welding) and sensing face (normal black lacquer) imitations of the Soviet radiometer with a relative error of 10; radiation measurement instruments used after 1993 were the pyroelectric (wound constantan copper) and sensing surface (dedicated optical black lacquer) automatic 
telemetry radiometer developed in China with a relative error of 0.5. Source data in the data set passed the quality control; the control content included format checks, missing data checks, threshold checks, major range checks, internal consistency checks, comprehensive analyses of quality control, and data quality mark. For quality control records that were suspicious, investigations were conducted to verify the data. The statistical results of Beijing meteorological station no. 54511 were also manually validated.

Vapor pressure and sunshine duration were obtained from the data sets of annual radiation values in China. The data set contained the annual value of 752 Chinese basic, datum ground, and automatic weather stations since 1951; the file type of the data set was ASCII. Data in the data set passed through strict quality control and inspection, whereas the data of 722 weather stations between 1971 and 2000 passed through extreme tests of statistical results and time consistency. The results show that the data are correct.

A total of 14 cities in China with different daylighting climate characteristics, namely, daylighting climate zone I: Yushu and Kunming, daylighting climate zone II: Erenhot and Xining, daylighting climate zone III: Beijing, Guangzhou, and Urumchi, daylighting climate zone IV: Changchun, Changsha, Xi'an, Shanghai, and Fuzhou, and daylighting climate zone V: Chongqing and Heihe, was included in this study (Figure 1). The annual solar irradiance, sunshine duration, geographic latitude, altitude, and vapor pressure values in these 14 cities in the past 50 years (from 1961 to 2010) were obtained. The missing past-year meteorological and radiation data in some cities were the main reasons for measurement or storage; however, the proportion was considerably low.

\section{Conversion of annual total illuminance data}

The annual luminous efficacy value of each city under different climate conditions can be obtained using Equation 1. Combined with the annual total irradiance value in the region, the annual total illuminance data in this region can be calculated by means of Equation 2 . The distribution of total illuminance values in the 14 cities is shown in Figure 2.

$$
E_{\mathrm{v}}=K_{G} \times E_{\mathrm{e}}
$$

\section{Research methods}

The accuracy of ordinary linear regression is affected by the significant inter-annual variation in total natural illuminance and the possible missing and abnormal values. The Mann-Kendall test method [14] or nonparametric test method can reveal the changing trend of time series; the method does not require samples to follow a specific distribution and cannot be affected by a few abnormal values [15]. The method does not involve statistical analyses and is suitable for data with abnormal distribution. Owing to the above-mentioned advantages, the Mann-Kendall test method has been widely applied in

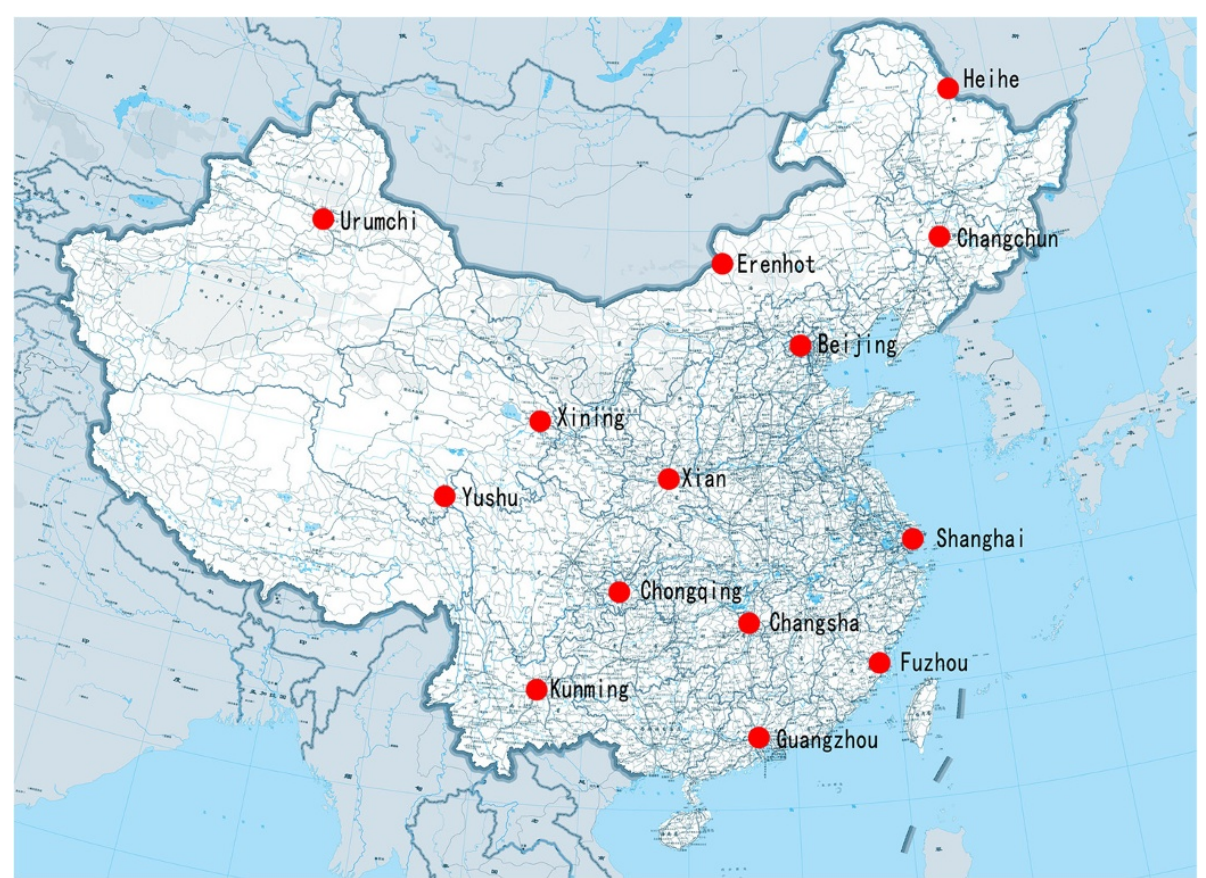

Figure 1 Location distribution of the 14 meteorological observation stations. 


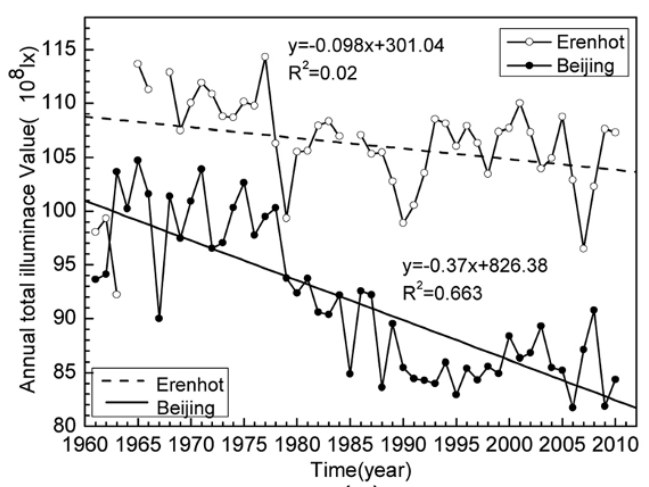

(a)

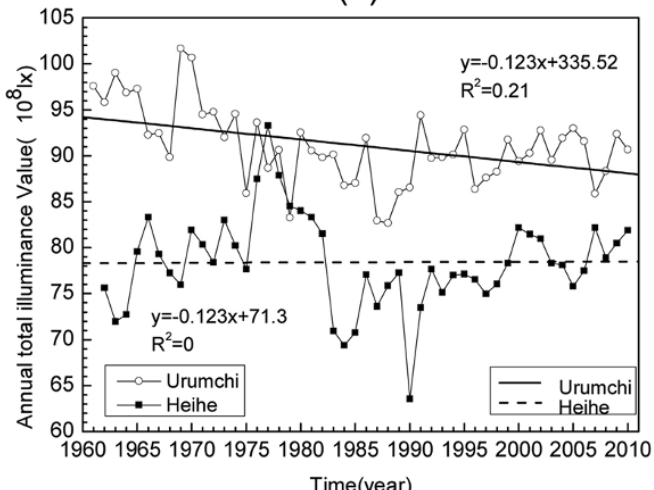

(c)

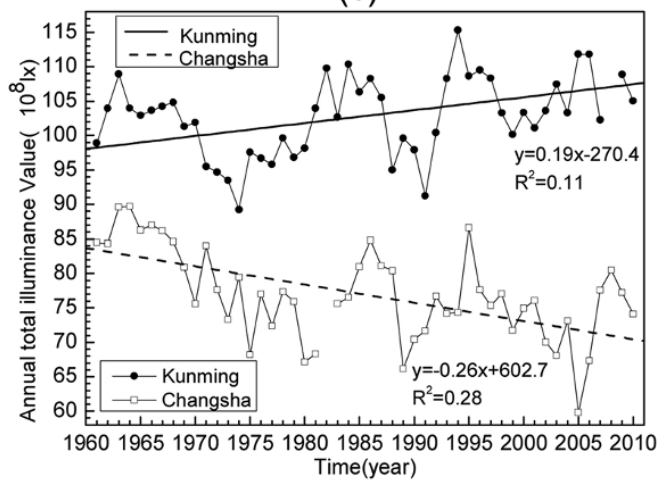

(e)

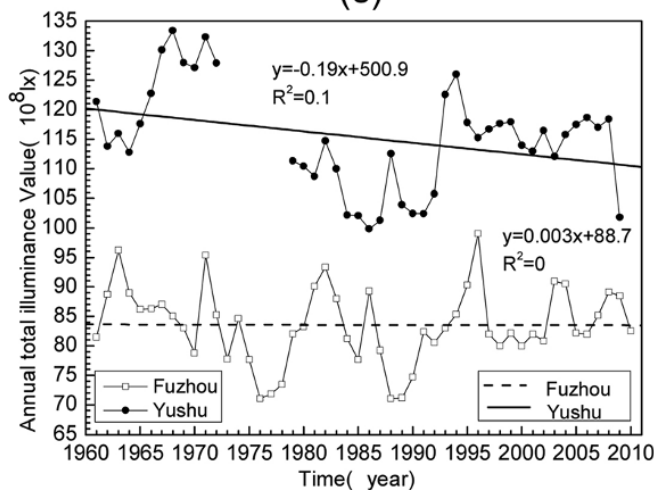

(g)

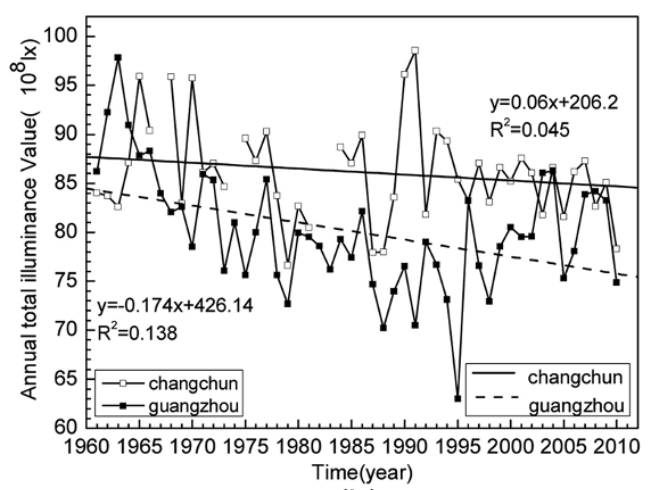

(b)

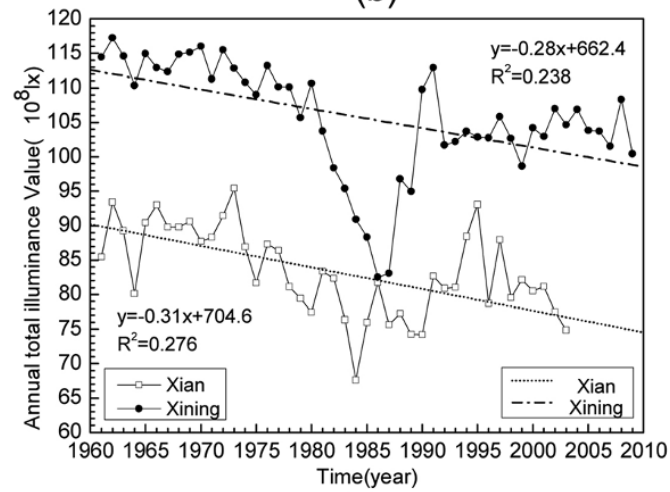

(d)

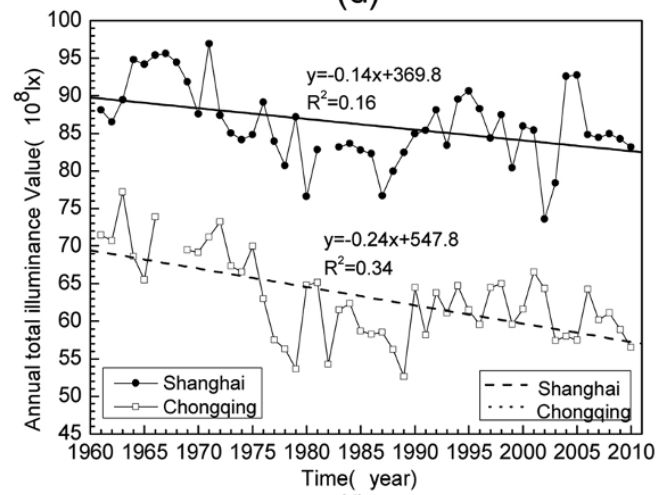

(f)

Figure 2 Inter-annual variation in annual total illuminance in typical Chinese light-climate regions and Sen's slope trend analysis. (a) Erenhot and Beijing, (b) Changchun and Guangzhou, (c) Urumchi and Heihe, (d) Xian and Xining, (e) Kunming and Changsha, (f) Shanghai and Chongqing, and (g) Fuzhou and Yushu. 
meteorology [16,17]. However, its application in natural light environment has not been reported until now. This study adopted the Mann-Kendall test method to study the characteristics and trends of natural illuminance changes in China with the aim of providing a basis and reference for the utilization of natural light and revision of daylighting standards.

\section{Trend analysis}

The trend analysis was conducted in two phases. First, the presence of a monotonic increasing or decreasing trend was tested using the nonparametric Mann-Kendall test. Second, the slope of a linear trend was estimated by means of the nonparametric Sen's slope estimator. The correlation coefficients of the meteorological data and time were also computed to determine the strength of the linear relationship among the variables.

\section{Mann-Kendall analysis}

We suppose that time series $\left(x_{1}, x_{2}, \ldots, x_{n}\right)$ has no trend. Statistics $S$ is calculated through the following calculation method.

$$
S=\sum_{k=1}^{n-1} \sum_{j=k+1}^{n} \operatorname{sgn}\left(x_{j}-x_{k}\right)
$$

where $S$ has a normal distribution, a mean value of 0 , and variance of $\operatorname{var}(S)=\frac{n(n-1)(2 n+5)}{18}$. The standard calculation method for normal statistics is provided below:

$$
Z=\left\{\begin{array}{l}
\frac{S-1}{\sqrt{\operatorname{var}(S)}}, S>0 \\
0, S=0 \\
\frac{S+1}{\sqrt{\operatorname{var}(S)}}, S<0 .
\end{array}\right.
$$

For a given confidence level $\alpha$ in the bilateral trend test, we suppose that the null hypothesis is unacceptable if $|Z| \geq Z_{1-\alpha / 2}$. The time series data exhibit an obvious increasing or decreasing trend at a confidence level of $\alpha$.

$Z$ follows a normal distribution. In this paper, the $Z$ value was tested at $90 \%, 95 \%$, and $99 \%$ levels of significance. The trend is said to be decreasing if $Z$ is negative and the absolute value is higher than the level of significance, whereas the trend is increasing if $Z$ is positive and higher than the level of significance. If the absolute value of $Z$ is less than the level of significance, no trend exists. These trends passed the significance test with confidence coefficients of 99\%, 95\%, and 90\%, thus indicating that the change trend is very obvious, obvious, and not obvious, respectively.

\section{Sen's slope estimator}

One of the most useful parametric models in detecting trends is the 'simple linear regression' model. However, the linear regression method requires the assumptions of normality of residuals [15]. Daylighting illuminance does not follow a normal distribution because of the influence of natural phenomena. Hence, Sen's slope estimator, which is a nonparametric method, was used to develop the linear models in the current study. This method offers many advantages in analyzing atmospheric data. Missing values are allowed, and the data do not need to conform to any particular distribution. Sen's method is insignificantly affected by single data errors or outliers [18]. To estimate the true slope of an existing trend (as change per year), Sen's nonparametric method was used. Sen's method can be employed in a study when the trend is linear:

$$
f(t)=Q^{\prime} \times t+B
$$

where $Q^{\prime}$ is the slope, $B$ is a constant, and $t$ is time. To obtain the slope estimate $Q^{\prime}$ in Equation 6, the slopes of all data value pairs are first calculated by using the following equation:

$$
Q^{\prime}=\operatorname{median}\left(\frac{x_{i}-x_{j}}{i-j}\right), \forall j<i
$$

where $1<j<i<n$;median represents the median function.

In this paper, we analyze the Mann-Kendall trend test by using the Mann-Kendall trend test feature in the XLSTAT-Time software package (Addinsoft, New York, NY, USA). XLSTAT is a Microsoft Excel (Microsoft, Albuquerque, NM, USA) statistical add-in that was first developed in 1995 to enhance the analytical capabilities of Excel. Trend analysis was conducted as follows: first, we implemented the Mann-Kendall trend test feature of the XLSTAT-Time software package in Excel; second, we defined the null hypothesis $\mathrm{H} 0$, which state that no trend exists in the series; third, we entered the time series and annual total illuminance series into Excel and then calculated the values of $S, \operatorname{var}(S)$, and Sen's slope $Q^{\prime}$; finally, we calculated the $Z$ value by Equation 4 . Using the $Q^{\prime}$ value, we can obtain the $B$ value in Equation 5 via Origin software analysis (OriginLab Corporation, Northampton, MA, USA).

\section{Correlation coefficient}

The correlation coefficient determines the strength of the linear relationship between two variables. $\mathrm{R}$ squared $\left(R^{2}\right)$, or the square of the correlation coefficient, is a fraction between 0.0 and 1.0. An $R^{2}$ value of 0.0 denotes that no correlation and linear relationship exists between $X$ and $Y$. By contrast, when $R^{2}$ approaches 1.0 , the 
correlation becomes strong, and all points lie on a straight line with a value of 1.0. The correlation coefficients between annual total illuminance value and time were calculated by using Origin 8.0 software.

\section{Mann-Kendall mutation test}

We suppose that a time series $\left(x_{1}, x_{2}, \ldots, x_{n}\right)$ exists. One order series, $m_{i}$, is constructed to represent the sample accumulative number of $x_{i}>x_{j}(1 \leq j \leq i) . d_{k}$ is defined as

$$
d_{k}=\sum_{1}^{k} m_{i}(2 \leq k \leq n) .
$$

The mean value and variance of $d_{k}$ can be approximately expressed as

$$
\begin{aligned}
& E\left(\mathrm{~d}_{k}\right)=\frac{k(k-1)}{4} \\
& \operatorname{var}\left(\mathrm{d}_{k}\right)=\frac{n(n-1)(2 n+5)}{72} \quad(2 \leq k \leq n) .
\end{aligned}
$$

Under the hypothesis that the time series is random and independent, the statistics is defined as

$$
U F_{k}=\frac{d_{k}-E\left(d_{k}\right)}{\operatorname{var}\left(d_{k}\right)}(k=1,2, \ldots, n)
$$

Given the significance level of $\alpha,\left|U F_{\mathrm{k}}\right|>U F_{\alpha / 2}$ means that the series has an obvious change trend. Time series $x_{\mathrm{i}}$ is arranged in a reverse order and is calculated with Equation 8 while ensuring that

$$
\left\{\begin{array}{l}
U B_{k}=-U F_{k} \\
k=n+1-k
\end{array} .\right.
$$

By analyzing statistical series $U F_{k}$ and $U B_{k}$, the change trend of series $x_{\mathrm{i}}$ can be further analyzed and the mutation time and region can be determined. $U F_{k}>0$ indicates that the series tends to increase; $U F_{k}<0$ indicates that the series tends to decrease. When the series exceed the credibility line, then they exhibit an obvious increasing or decreasing trend. If an intersection point exists between the curves of $U F_{k}$ and $U B_{k}$ and falls between the credibility lines, the corresponding time of the intersection point is the starting moment of mutation.

According to the Mann-Kendall mutation testing methods, we programmed and calculated the value of $U F_{k}$ and $U B_{k}$ by using the Perl programming language. The Perl programming language is a highly capable, feature-rich programming language with over 25 years of development. By entering a time series value $\left(x_{1}, x_{2}, \ldots, x_{n}\right)$ in the program, the corresponding values of $U F_{k}$ and $U B_{k}$ could be obtained. We entered the values of $U F_{k}$ and $U B_{k}$ and the corresponding time to the Origin 8.0 software and then drew the corresponding graph.

\section{Results}

\section{Change trend analysis of annual total illuminance}

The statistical values $Z$, Sen's slope value $Q^{\prime}$, statistical average value $\left(10^{8} \mathrm{~lx}\right)$, regression equation and $R^{2}$ of annual total illuminance in each city were obtained using the Mann-Kendall trend test method based on a series of annual total illuminance values in 14 cities in typical Chinese climate regions from 1961 to 2010 (Table 1).

A positive $Z$ value represents an increasing trend, whereas a negative $Z$ value represents a decreasing trend. Absolute $Z$ values equal to or greater than 1.64, 1.96, and 2.56 indicate that the values passed the significance tests with confidence coefficients of $90 \%, 95 \%$, and 99\%, respectively. Table 1 shows that Beijing, Guangzhou, Xi'an, Xining, Shanghai, Changsha, and Chongqing passed the significance test with a confidence coefficient of $99 \%$, indicating that the change trends in these cities are very obvious. Kunming and Erenhot passed the significance test with a confidence coefficient of $95 \%$, indicating that the change trend in these cities is obvious. Changchun, Yushu, Heihe, and Fuzhou failed to pass the significance test (confidence coefficient of 90\%), which means that no change trend exists.

Slope value $Q^{\prime}$ represents the annual total illuminance change. A positive $Q^{\prime}$ value denotes an increasing trend, whereas a negative $Q^{\prime}$ value denotes a decreasing trend. Table 1 shows that only the annual total illuminance changes in Kunming and Heihe exhibit positive values. The other cities exhibit a decreasing trend. Beijing's total illuminance has a strong correlation with Sen's slope curve; other cities' total illuminance has weak or no correlation with Sen's slope curve. The annual total illuminance change in Beijing is within the maximum range of $-3.7 \times 10^{8} \mathrm{~lx} / 10 \mathrm{a}$ and that in Fuzhou is within the minimum range of $-0.026 \times 10^{8} \mathrm{~lx} / 10 \mathrm{a}$. The annual total illuminance change in Kunming is within the maximum range $1.88 \times 10^{8} \mathrm{~lx} / 10 \mathrm{a}$ and that in Heihe is within the minimum range of $0.036 \times 10^{8} \mathrm{~lx} / 10 \mathrm{a}$.

\section{Mutation analysis of annual total illuminance}

The annual total illuminance mutation map (shown in Figure 3) of 14 cities in typical Chinese light-climate regions was drawn using the Mann-Kendall mutation test method. The change trends of annual total natural light illuminance in 14 cities were determined through analysis.

The annual total natural light illuminance in Beijing (Figure 3a) presented a slow increasing trend prior to 1975 and maintained a decreasing trend afterward. Mutation occurred in 1978, after which the decreasing trend became more obvious. The statistical value continued to increase after it exceeded the critical confidence coefficient of 1.96 in 1980, indicating that the annual total natural light illuminance in Beijing declined significantly. 
Table 1 Mann-Kendall statistics of annual total illuminance in typical Chinese climate regions

\begin{tabular}{|c|c|c|c|c|c|c|}
\hline Cities & $Z$ value & Average annual total value $\left(10^{8} \mathrm{Ix}\right)$ & Trend & $Q^{\prime}$ & Regression equation & $R^{2}$ value \\
\hline Beijing & -5.571 & 90.9 & Decrease & -0.37 & $y=-0.37 x+826.38$ & 0.663 \\
\hline Changchun & -1.477 & 86.13 & Decrease & -0.06 & $y=0.06 x+206.2$ & 0.045 \\
\hline Erenhot & -2.18 & 106.2 & Decrease & -0.098 & $y=-0.098 x+301.04$ & 0.02 \\
\hline Guangzhou & -2.71 & 80.3 & Decrease & -0.17 & $y=-0.174 x+426.14$ & 0.138 \\
\hline Heihe & 0.078 & 78.4 & Increase & 0.0036 & $y=-0.123 x+71.3$ & 0 \\
\hline Urumchi & -3.04 & 91.1 & Decrease & -0.123 & $y=-0.123 x+335.52$ & 0.21 \\
\hline Xi'an & -3.7 & 83.3 & Decrease & -0.31 & $y=-0.31 x+704.6$ & 0.276 \\
\hline Xining & -4.215 & 105.6 & Decrease & -0.28 & $y=-0.28 x+662.4$ & 0.238 \\
\hline Yushu & -1.3 & 113.9 & Decrease & -0.19 & $y=-0.19 x+500.9$ & 0.1 \\
\hline Fuzhou & -0.044 & 83.5 & Decrease & -0.0026 & $y=0.003 x+88.7$ & 0 \\
\hline Kunming & 2.357 & 102.8 & Increase & 0.188 & $y=0.19 x-270.4$ & 0.11 \\
\hline Shanghai & -2.56 & 86.1 & Decrease & -0.14 & $y=-0.14 x+369.8$ & 0.16 \\
\hline Changsha & -3.69 & 76.9 & Decrease & -0.26 & $y=-0.26 x+602.7$ & 0.28 \\
\hline Chongqing & -3.96 & 63 & Decrease & -0.24 & $y=-0.24 x+547.8$ & 0.34 \\
\hline
\end{tabular}

Annual total natural light illuminance in Changchun (Figure 3b) presented a slow decreasing trend prior to 1964, maintained an increasing trend in 1965 and 1978, and maintained a decreasing trend after 1978. The statistical values did not exceed the critical confidence coefficient of 1.96, indicating that annual total natural light illuminance in Changchun decreased after 1978 (the trend was insignificant).

Annual total natural light illuminance in Guangzhou (Figure 3b) presented a slow increasing trend in 1965 and maintained a decreasing trend afterward. Mutation occurred in 1967, after which the decreasing trend became more obvious. The statistical values exceeded the critical confidence coefficient of 1.96 after 1970, indicating that annual total natural light illuminance in Guangzhou declined significantly after 1970.

The annual total natural light illuminance in Erenhot (Figure 3a) presented a slow increasing trend prior to 1979 and maintained a decreasing trend afterward. Mutation occurred in 1982, after which the decreasing trend became more obvious. The statistical values exceeded the critical confidence coefficient of 1.96 from 1990 to 1995, 1998 to 1999, and 2007 to 2010, indicating that annual total natural light illuminance in Erenhot declined significantly in these years.

The annual total natural light illuminance in Urumchi (Figure 3c) maintained a decreasing trend except in 1963. The statistical values exceeded the critical confidence coefficient of 1.96 after 1977, indicating that annual total natural light illuminance in Urumchi declined significantly after 1977.

The annual total natural light illuminance in Xi'an (Figure 3d) increased (with fluctuation) prior to 1975.
Mutation occurred in 1976, after which the decreasing trend became more obvious. The statistical values exceeded the critical confidence coefficient of 1.96 after 1980, indicating that annual total natural light illuminance in Xi'an declined significantly after 1980.

The annual total natural light illuminance in Xining (Figure 3d) increased (with fluctuation) prior to 1973. Mutation occurred in 1974, after which the decreasing trend became more obvious. The statistical values exceeded the critical confidence coefficient of 1.96 after 1978, indicating that annual total natural light illuminance in Xining declined significantly after 1978.

The annual total natural light illuminance in Heihe (Figure 3c) presented an increasing trend prior to 1988. Mutation occurred in 1964, after which the increasing trend became more obvious. The statistical values exceeded the critical confidence coefficient of 1.96 from 1976 to 1983, indicating that annual total natural light illuminance in Heihe increased significantly. However, after 1988, the annual total natural light illuminance in Heihe maintained a decreasing trend. The statistical values did not exceed the critical confidence coefficient of 1.96, indicating that the annual total natural light illuminance in Heihe presented a decreasing trend; however, the trend was not significant.

The annual total natural light illuminance in Kunming (Figure 3e) presented an increasing trend prior to 1967 and gradually decreased afterward. The statistical values exceeded the critical confidence coefficient of 1.96 from 1972 to 1980 , indicating that annual total natural light illuminance in Kunming decreased significantly. Mutation occurred in 1992, after which an increasing trend was presented. The statistical values exceeded the critical 


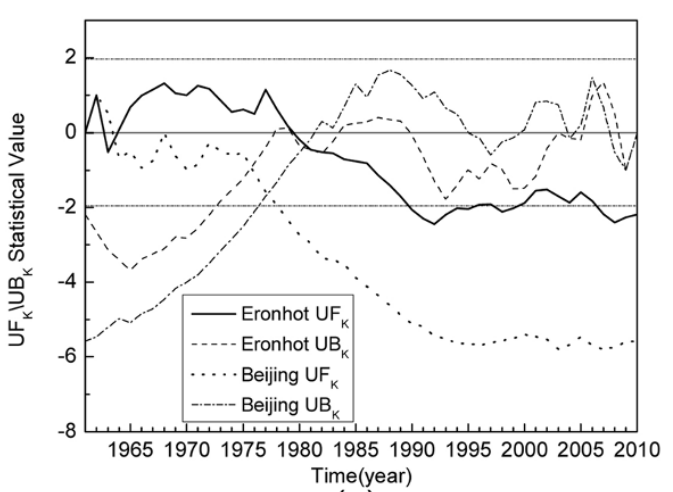

(a)

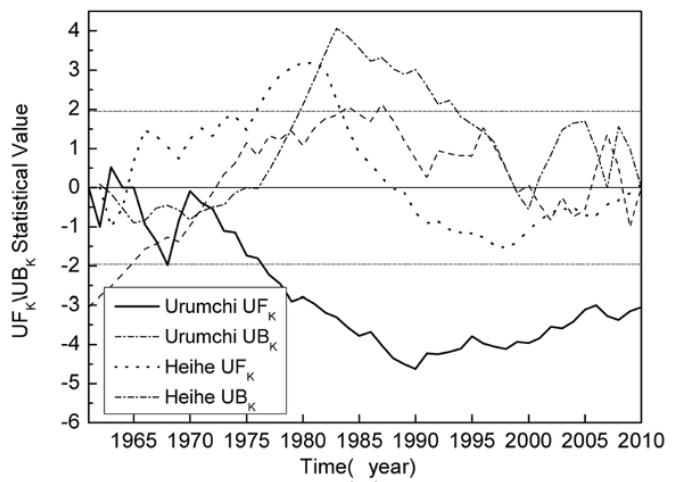

(c)

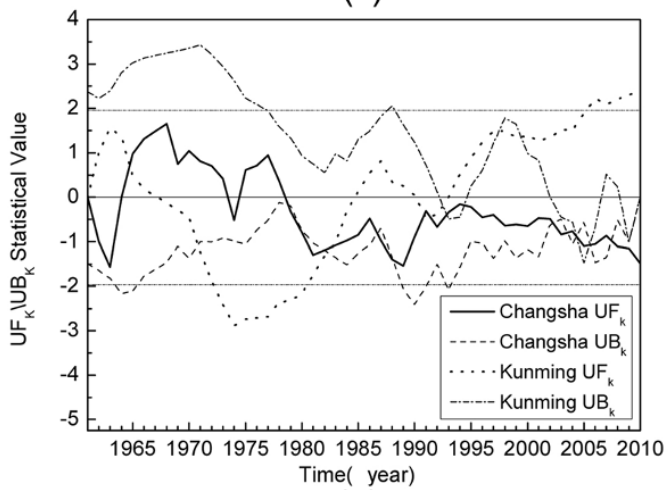

(e)

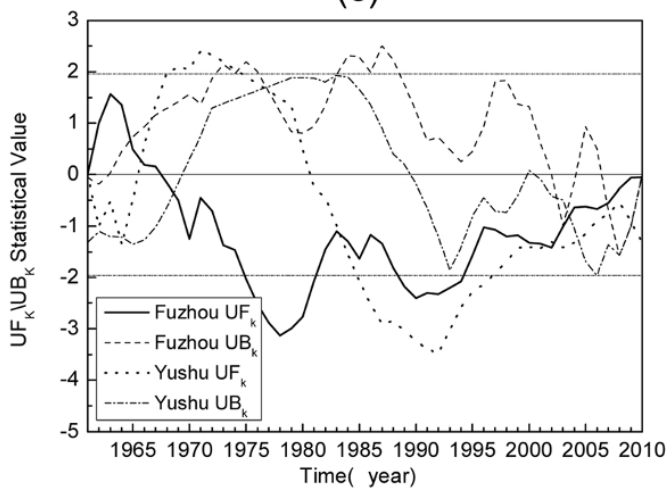

(g)

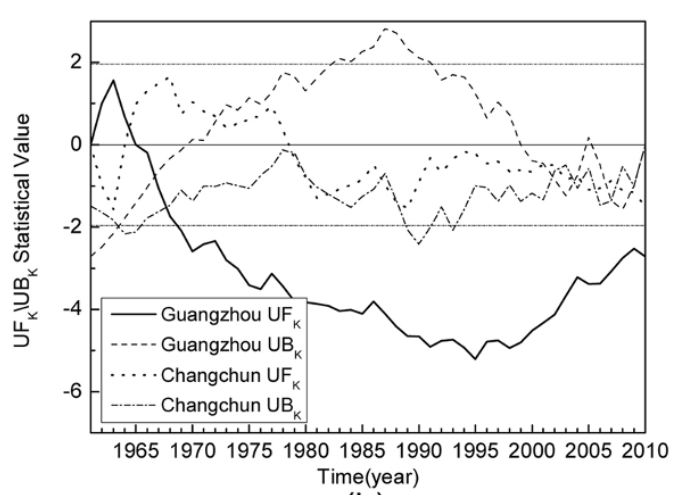

(b)

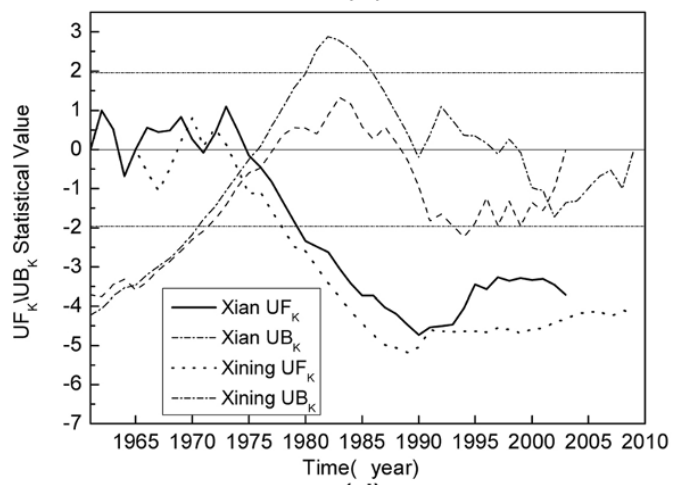

(d)

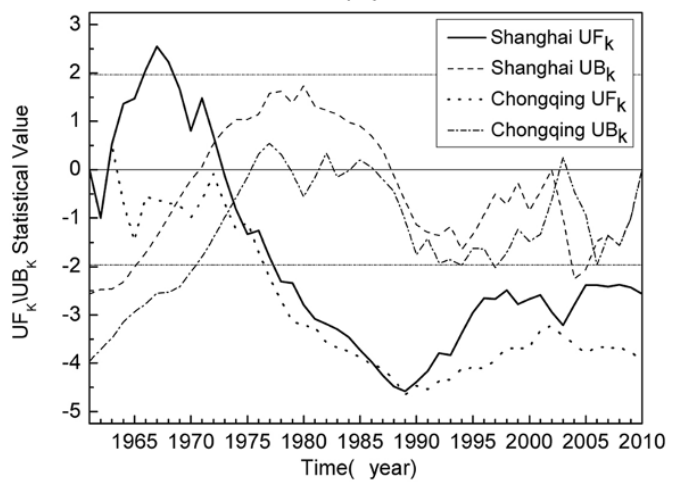

(f)

Figure 3 Mann-Kendall mutation test of annual total illuminance in typical Chinese light-climate regions. (a) Beijing and Erenhot, (b) Changchun and Guangzhou, (c) Urumchi and Heihe, (d) Xi'an and Xining, (e) Kunming and Changsha, (f) Shanghai and Chongqing, and (g) Fuzhou and Yushu. 
confidence coefficient of 1.96 from 2005 to 2010, indicating that annual total natural light illuminance in Kunming increased significantly.

Annual total natural light illuminance in Fuzhou (Figure 3g) presented an increasing trend prior to 1967 and decreased gradually afterward. Mutation occurred in 1965, after which a rapid decreasing trend was presented. After the mutation in 2007, the decrease in annual total natural light illuminance in Fuzhou slowed down. The statistical values exceeded the critical confidence coefficient of 1.96 from 1975 to 1981 and 1989 to 1994, indicating that the annual total natural light illuminance in Fuzhou declined significantly in these years.

The annual total natural light illuminance in Yushu (Figure 3g) presented a decreasing trend prior to 1965. Mutation occurred in 1964, and a gradual decreasing trend was presented from 1965 to 1980 . The statistical values exceeded the critical confidence coefficient of 1.96 from 1968 to 1974, indicating that annual total natural light illuminance increased significantly in this period. The decreasing trend was maintained after 1980, and the statistical values exceeded the critical confidence coefficient of 1.96 from 1985 to 1996 . The decreasing trend was obvious in this period. After the mutation in 2004, annual total natural light illuminance in Yushu decreased gradually.

The annual total natural light illuminance in Shanghai (Figure 3f) presented an increasing trend prior to 1973 and gradually decreased afterward. Mutation occurred in 1973, after which the decrease became rapid. The statistical values exceeded the critical confidence coefficient of 1.96 after 1978, indicating that annual total natural light illuminance in Shanghai declined significantly after 1978.

The annual total natural light illuminance in Changsha (Figure 3e) increased (with fluctuation) prior to 1978 and gradually decreased afterward. The statistical values failed to exceed the critical confidence coefficient of 1.96, indicating that the annual total natural light illuminance in Xining presented a decreasing trend; however, the trend was not significant.

The annual total natural light illuminance in Chongqing (Figure 3f) maintained a decreasing trend except in 1963. Mutation occurred in 1974, after which the decrease became rapid. The statistical values exceeded the critical confidence coefficient of 1.96 after 1977, indicating that the annual total natural light illuminance in Urumchi declined significantly after 1977.

\section{Discussion}

\section{Trend and mutation of natural illuminance levels in 14} Chinese cities

The overall change trends of annual total illuminance values in typical Chinese daylighting climate regions are as follows. The changes in Beijing, Guangzhou, Urumchi, Xian, Xining, Kunming, Shanghai, Changsha, and Chongqing were extremely obvious. The change in Erenhot was obvious. The changes in Changchun and Yushu were not obvious, and no change was observed in Heihe and Fuzhou.

Total natural light illuminance values decrease significantly in some cities, e.g., Beijing and Chongqing. According to statistics, the decrease of annual total illuminance value exceeds 10\% during 1961 to 2010. Daylighting design standards in China are based on the natural daylighting luminance value. This change will cause daylighting design errors that cannot be ignored. Thus, the daylighting design standard illuminance value in China should be corrected.

The inter-annual change trends of annual total illuminance values in cities in typical Chinese light-climate regions are as follows: The annual total illuminance values in Chongqing and Urumchi decreased year by year. The values increased initially and then decreased in Beijing, Shanghai, Changsha, Guangzhou, Erenhot, Xi'an, Xining, and Heihe. The values increased initially, decreased, and then increased again in Changchun and Yushu. The annual total illuminance values decreased initially, increased, and then decreased again in Kunming.

\section{Variations in the influencing factors of natural light illuminance}

Natural light is the visible part of solar radiation; thus, the effects of solar radiation corresponding to meteorological factors also affect natural illumination changes. Solar radiation that reach the ground is influenced by clouds, atmosphere (including basic atmospheric composition, aerosols, and water vapor), and changes in solar radiation. We discuss the influencing factors of natural light illuminance in the following subsections.

\section{Cloud}

Clouds have a significant impact on natural lighting climates. Clouds affect not only the natural light reaching the ground but also the sky luminance distribution. Researchers studied trends in cloud cover in China by using cloud cover data from ground-based observations. The results showed that the total cloud cover has been decreasing in China since 1950 [19]. In general, changes in the cloud cover will lead to a decrease or increase in natural light.

However, a long-term reduction in the overall cloud cover trends of China cannot explain the decreasing trend of natural light illuminance. The impact of clouds on natural light is quite complex. Different heights, types, and thicknesses, as well as different physical, chemical, and optical properties of clouds, will produce 
different effects on solar radiation. Thus, although changes in existing total cloud cover variation cannot explain the phenomenon of natural light, we cannot deny that clouds play an important role in natural illumination.

\section{Aerosol}

Aerosol is another important and complex influencing factor of natural light. Aerosol not only reflects, scatters, or absorbs sunlight but also produces indirect effects by changing the microphysical nature of clouds. The effects of aerosols on sunlight vary. An increase in aerosol content increases atmospheric optical thickness, thus correspondingly reducing the natural illumination that reaches the surface.

Aerosols can usually be divided into natural and anthropogenic aerosols. Natural aerosols mainly refer to aerosols that are released into the atmosphere by volcanic eruption. Volcanic eruptions in 1982 and 1991 affected the global natural light illuminance. The volcanic eruptions reduced the direct light from the sun but increased the scattered light. We do not discuss this change further because this phenomenon is unpredictable. Anthropogenic aerosols are generated from fossil energy use emissions. Sulfates and black carbon contribute one third to the global aerosol optical thickness [20]. Natural light illuminance is inversely correlated with aerosol optical thickness. Therefore, an increase in anthropogenic aerosols increases the atmospheric optical thickness correspondingly and decreases ground illumination [12].

Motor vehicles have been rapidly increasing in China because of economic development. A large number of emissions generated by motor vehicles and fossil energy increases atmospheric pollution across China year after year. Aerosol thickness correspondingly increases, particularly severe fog and haze, thus resulting in the worsening of air pollution in recent years. Air pollution also affects the natural illumination changes in China.

\section{Water vapor}

Water vapor absorbs sunlight. Research indicates that the global average of columnar water vapor content is $25 \mathrm{~mm}$. For every 1\% increase in solar radiation, water vapor content increases from $3 \mathrm{~mm}$ to $6 \mathrm{~mm}$ [21]. Moisture content increases by only $0.5 \mathrm{~mm}$ in China between 1971 and 1990 [22]. Thus, water vapor changes will have insignificant effects on natural illumination.

\section{Atmospheric molecular scattering and absorption}

Atmospheric gas molecules also scatter and absorb sunlight. However, human activity has changed atmospheric gas composition in recent decades (such as $\mathrm{CO}_{2}$ ). Given that gas composition has low levels of ingredients in the atmosphere, the effect of atmospheric gas on natural illumination can be neglected.

\section{Solar activity}

Solar activity changes are mainly observed by satellite. To date, four independent space-based instruments directly observe total solar irradiance [23]. Solar radiation is typically an 11-year cycle and the amount of change is usually small and not more than $1 \%$ [16]. Therefore, the effect of solar activity can be ignored.

\section{Conclusions}

On the basis of the luminous efficacy model, the total natural light illuminance values of 14 Chinese cities in different light-climate regions were calculated. We used Mann-Kendall trends and Mann-Kendall mutation analysis to study the changes in natural light illuminance in 14 cities.

The annual total natural light illuminance values in 14 cities have nonuniform changes. Except for the increasing trend of Kunming and Heihe, other cities exhibit an overall downward trend.

The annual total illuminance values of natural light in some cities significantly decrease. The decrease in annual total illuminance values has exceeded $10 \%$ during the past 50 years, thus affecting the accuracy of architectural daylighting design. The total change trend of natural light illuminance has an insignificant association with Chinese light-climate regions. Therefore, to meet the needs of architectural daylighting design and building energy efficiency, Chinese light-climate regions should be adjusted and the total natural light illuminance standard value should be corrected.

Many factors influence natural illuminance; the major factors include cloud cover and aerosols. In recent years, air pollution in China has increasingly caused variations in total natural light illumination values. Other influencing factors (e.g., water vapor, atmospheric molecular scattering and absorption, and solar activity) have a minor effect on total natural light illumination.

\section{Abbreviations}

a: confidence level; $d_{k}$ : sample accumulative number; $e$ : annual average absolute humidity $(\mathrm{hPa})$; $E\left(d_{k}\right)$ : mean value; $E_{\mathrm{e}}$ : annual total irradiance value $\left(\mathrm{W} \times \mathrm{h} / \mathrm{m}^{2}\right) ; E_{\mathrm{v}}$ : annual total illuminance value $(\mathrm{Ix}) ; H$ : altitude $(\mathrm{m}) ; K_{\mathrm{G}}$ : the value of annual luminous efficacy $\left(1 \mathrm{x} / \mathrm{w} \times \mathrm{m}^{-2}\right) ; m_{i}$ : order series; $N$ : geographic latitude $\left({ }^{\circ}\right)$; $Q^{\prime}$ : Sen's slope; $S$ : statistical value of $x_{i} T$ : monthly average sunshine duration (h); $U F_{k}$ : statistical series value of $d_{k} ; U B_{k}$ : statistical series value of $d_{k i} \operatorname{var}(S)$ : variance; $Z$ : standard normal statistics of $x_{i}$.

\section{Competing interests}

The authors declare that they have no competing interests.

\section{Authors' contributions}

Authors HY, WA, and HH conceived the study, developed the concept, designed the study, carried out the empirical research, and drafted the manuscript. All authors read and approved the final manuscript. 


\section{Acknowledgements}

This work was financially supported by the Fundamental Research Funds for the Central Universities (project no. 106112013CDJZR190004), the Nationa Natural Science Foundation of China - Youth Fund (grant nos. 50908239 and 51108479), Chongqing Municipal Construction Science and Technology Program (City Science 2011 no. 2-64) and the open project of State Key Laboratory of Subtropical Science (grant no. 2012KA01).

\section{Author details}

${ }^{1}$ Faculty of College of Architecture and Urban Planning, Chongqing University, Chongqing 400045, China. ${ }^{2}$ Faculty of Key Laboratory of Chinese Education Ministry for Construction and New Technology of Mountain Cities, Chongqing University, Chongqing 400045, China. ${ }^{3}$ Faculty of School of Architecture, Tianjin University, Tianjin 300072, China.

Received: 28 June 2013 Accepted: 11 November 2013

Published: 26 November 2013

\section{References}

1. Qikuang W (1987) The luminous efficacy of total solar radiation and its application in the calculation of illumination climate. Acta Meteorological Sinica 45(5):290-296

2. Qikuang W (1987) The temporal and spatial distribution of total illumination in China. Acta Energiae Solaris Sinica 8(4):347-351

3. Ying H, Hua-song M, Li Q (2012) Sky luminance distribution types in China. J Cent South Univ Technol 19(3):777-782

4. Central Bureau of CIE (1994) Technical report. Guide to recommended practice of daylight measurement. Color Res Appl 20(1):80

5. Littlefair PJ (1988) Measurements of the luminous efficacy of daylight. Light Res Technol 20:177-188

6. Aydinli S, Krochman J (1983) Data on daylight and solar radiation. Draft for CIE TC 4:2

7. Robledo L, Soler A (2000) Luminous efficacy of global solar radiation for clear skies. Energy Convers Manag 4:1769

8. Chung TM (1992) A study of luminous efficacy of daylight in Hong Kong Energy and Buildings 19:45-50

9. Robledo L, Soler A (2001) On the luminous efficacy of diffuse solar radiation Energy Convers Manag 42:1181-1190

10. Perez R, Ineichen P, Seals R, Michalsky J, Stewart R (1990) Modeling daylight availability and irradiance components from direct and global irradiance. Sol Energy 44:271-289

11. Shen Y, Zhao Z, Shi G (2008) The progress in variation of surface solar radiation, factors and probable climate effects. Advances in Earth Science 23(9):915-923

12. Streets DG, Yu C, Wu Y, Chinc M, Zhaod Z, Hayasakae T, Shif G (2008) Aerosol trends over China, 1980-2000. J Atmos Res 88:174-182

13. Alpert P, Kishcha P, Kaufman YJ, Kaufman YJ, Schwarzbard R (2005) Global dimming or local dimming? Effect of urbanization on sunlight availability. Geophys Res Lett 32:17

14. Kendall M (1975) Multivariate analysis. Charles Griffin \& Company, London

15. McBean E, Motiee H (2008) Assessment of impact of climate change on water resources: along term analysis of the Great Lakes of North America. Hydrol Earth Syst Sci 12:239-255

16. Hamed KH (2009) Exact distribution of the Mann-Kendall trend test statistic for persistent data. Hydrolohy 1:86-94

17. Yeling L, Xiaoli Z, Aiqin Z (2012) Analysis of precipitation trend in the Guanzhong Basin based on the Mann-Kendall method. Yellow River 34(2):28-33

18. Salmi T, Määttä A, Anttila P, Ruoho-Airola T, Amnell T (2002) Detecting trends of annual values of atmospheric pollutants by the Mann-Kendall test and Sen's slope estimates -the Excel template application makesens. Finnish Meteorological Institute Publications on Air Quality No. 31, Helsinki, Finland

19. Qi Z, Yueging L, Quanliang C, Jingxuan R (2011) Temporal and spatial distributions of cloud cover over Southwest China in recent 46 years. Plateau Meteorology 30(2):339-348

20. Streets DG, Wu Y, Chin M (2006) Two-decadal aerosol trends as a likely explanation of the global dimming/brightening transition. Geophys Res Lett 33:L15806, doi:10.1029/2006GL026471
21. Ramanathan V, Vogelmann AM (1997) Greenhouse effect, atmospheric solar absorption and the Earths radiation budget: from the Arrhenius-Langley era to the 1990s. Ambio 26:38-46

22. Zhai PM, Eskridge RE (1997) Atmospheric water vapor over China. Climat 10:2643-2652

23. Fröhlich C, Lean J (2004) Solar radiative output and its variability: evidence and mechanisms. Astron and Astrophys Rev 12:273-320, doi:10.1007 /s00159-004-0024-1

doi:10.1186/2192-0567-3-22

Cite this article as: He et al:: The trend of natural illuminance levels in 14 Chinese cities in the past 50 years. Energy, Sustainability and Society 2013 3:22.

\section{Submit your manuscript to a SpringerOpen ${ }^{\circ}$ journal and benefit from:}

- Convenient online submission

- Rigorous peer review

- Immediate publication on acceptance

- Open access: articles freely available online

- High visibility within the field

- Retaining the copyright to your article

Submit your next manuscript at $>$ springeropen.com 